The impact of probation and parole officers' attitudes about offenders on professional practices

\author{
Lacey Schaefer \& Gemma C. Williams \\ School of Criminology and Criminal Justice \\ Griffith Criminology Institute \\ Griffith University
}

Australia

Submitted to

Corrections: Policy, Practice and Research 


\begin{abstract}
There is a large literature examining public attitudes toward offenders, but fewer studies have examined the perceptions held by criminal justice actors. While many projects evaluate the role orientations of these staff, research rarely investigates the beliefs these individuals hold about the offenders they work with. This study addresses this gap through a survey of probation and parole staff, measuring how their attitudes toward the clients they work with influence supervision strategies, role orientations, job burnout and stress, and the use of case management tools. Results indicate that probation and parole staff who are generally pessimistic about offenders and see crime as a personal choice are more compliant with assessment and case management tools, while officers who are optimistic about offenders' ability to change and see crime as a consequence of circumstance are more likely to be noncompliant with the data entry process in the completion of risk and needs instruments. These findings provide important insights into the motivations of community corrections staff and suggest that work is needed to translate best practices into routine practices.
\end{abstract}

Keywords: probation and parole, case management, assessment, attitudes toward offenders, professional discretion, professional override 


\section{The impact of probation and parole officers' attitudes about offenders on professional practices}

Much criminological research has been dedicated to the accurate prediction and appropriate classification of offenders, with the aim of pinpointing individual traits which precede crime. Such knowledge underpins tailored criminal justice responses, facilitating both public safety and rehabilitation, in a cost-effective manner (Miller \& Maloney, 2013). Risk assessments have become more widely utilized in correctional practices and currently guide decision-making in a range of areas such as offender classification, levels of supervision, service provisions, and case plan stipulations (Andrews, Bonta, \& Wormith, 2006). The evolution of risk and needs assessments have improved the accuracy and consistency of outcomes by moving away from subjective, clinical judgements to more standardized, evidence-based measurements (Andrews \& Bonta, 2010). Given the broad application of offender assessment in correctional services - from making imprisonment and release decisions, to informing supervision intensity and order conditions, to influencing treatment priorities and placements - accurate results are fundamental to successful outcomes. However, assessment processes and results are sometimes misused, manipulated, or ignored when formulating individual case plans (Miller \& Maloney, 2013; Schaefer \& Williamson, 2018), and little is understood about the predictors of (non)compliance with assessments and case management tools.

One logical precipitator of how risk and needs assessments are (mis)used may be the sentiments of the actor about the population they are working with; specifically, corrections practitioners may approach the instrument with preconceived notions about that offender particularly or all offenders generally, and those ideas may influence how the assessment is completed or how the results are utilized. Yet despite this presumed link between attitudes and actions among correctional staff, it has been largely ignored empirically. While public attitudes toward offenders have been explored extensively in the literature, much less is 
known regarding attitudes of criminal justice personnel. The current study addresses this gap by examining the perceptions of community corrections staff, offering an important glimpse into how these attitudes influence the professional practices that go on to impact the use of offender assessments. Although the research evidence is clear in demonstrating that actuarial offender assessments are a necessary component of effective correctional practices, we do not yet understand whether staff are using these validated instruments as prescribed, nor do we know what motivates misuse when it does occur. An understanding of these relationships is necessary to estimate how corrections staff approach and utilize these tools, which have become integral to contemporary probation and parole practices.

\section{Attitudes toward offenders}

Existing research measuring participants' attitudes about offenders has largely focused on public perceptions, which have important implications for political agendas (Roberts, 2018). Studies generally find that education, perceptions of crime, and reliance on mainstream media are strong predictors of attitudes about offenders and punishment (Spiranovic, Roberts, \& Indermaur, 2012). Additionally, political orientation is frequently predictive of ideas about criminality and subsequent ideas for sentencing and sanctions; generally, conservative individuals are more likely to have a pessimistic view of offenders and favor harsher criminal justice responses, while liberal/progressive individuals tend to point toward situational criminogenic factors and favor treatment-oriented approaches (Rade, Desmarais, \& Mitchell, 2016).

In contrast, however, much less is known about the attitudes of criminal justice actors toward the offenders they work with. What is known, is that the general attitudes held by criminal justice personnel influences the way in which they perform their duties. Correctional officers have not been found to echo the call from the public for harsher punishment, generally favoring a more rehabilitative approach (Farkas, 1999), or a balanced orientation 
between treatment and control (Fulton, Stichman, Travis, \& Latessa, 1997). Demographic variables of correctional officers are also predictive of work orientations and performance. Gender is associated with officer orientation, though the research is mixed. It has been documented that female officers are more rehabilitation-oriented and align more with the human service aspect of their role (Maahs \& Pratt, 2001; Hemmens \& Stohr, 2000). In contrast, Farkas (1999) found female officers to exhibit more punitive attitudes and increased concern for corruption of authority, but also an inclination toward counselling roles, speculating that punitive attitudes could be the result of the difficulties experienced by some women working in a male-dominated correctional setting. Age and tenure are other factors that influence officer orientation, with some studies showing that older and more experienced officers favor rehabilitation (Farkas, 1999; Hemmens \& Stohr, 2000), while others demonstrate that new staff have a greater human service orientation to their role, with more time on the job generating cynicism and more punitive perspectives on punishment (Beijersbergen, Dirkwager, Molleman, van der Laan, \& Nieuwbeerta, 2015).

In addition to demographic characteristics, officers' attitudes can be further influenced by work-related dynamics. Role conflict, characterized by confusion about seemingly incompatible goals of the corrections system, predicts a greater desire for social distance, reduced punitive attitudes, and less support for counselling roles (Farkas, 1999). Furthermore, negative job attitudes are more prolific in female and minority officers, and those with higher levels of education (Maahs \& Pratt, 2001). Existing research regarding officer orientation and the associated impact on attitudes toward punishment tends to focus on correctional officers that supervise inmates in institutional settings. It remains unknown whether these findings are replicated in samples of community corrections staff. Within probation and parole research, studies examining the attitudes of staff emphasize their orientations to their supervision practices (e.g., whether the officer favors a treatment or 
control style of case management; Fulton, Stichman, Travis, \& Latessa, 1997; Schwalbe \& Maschi, 2009).

Far fewer studies have examined the attitudes of correctional staff about offenders directly; of those studies that do exist, they largely examine the attitudes of treatment providers toward sex offenders specifically (see, for example: Conley, Hill, Church, Stoeckel, \& Allen, 2011; Craig, 2005; Nelson, Herlihy, \& Oescher, 2002). Moreover, there is a dearth of research that investigates the impact of these offender-specific attitudes on actual practices. This is an unfortunate research gap, given that the empirical evidence for more than 50 years has demonstrated that the orientation of supervising officers impacts supervision practices and adherence to the principles of effective correctional intervention (Whetzel, Paparozzi, Alexander, \& Lowenkamp, 2011). But what impacts this orientation? How do the attitudes or probation and parole staff about the offenders they supervise impact their orientation and professional practices? Toward this end, the current study investigates the attitudes held by probation and parole staff toward their clients, going on to examine how those attitudes impact their role orientations, supervision strategies, levels of job burnout and stress, and (non)compliance with the completion of assessment and case management tools.

\section{Offender assessments}

Assessment is a crucial element of effective correctional intervention. The RiskNeeds-Responsivity (RNR) model is the dominant framework currently guiding effective correctional programs and rehabilitative efforts (Andrews \& Bonta, 2010). According to the model, the level of intervention should be commensurate with the level of risk of the offender, with the aim of targeting empirically supported dynamic risk factors, delivered in accordance with the individual's cognitive abilities, motivations, and learning style (Andrews et al., 2006). Consequently, the accurate identification of risk, criminogenic needs, and responsivity considerations is vital. Research consistently illustrates the weak predictive validity of 
unstructured professional judgement, in comparison to standardized, empirically driven actuarial risk assessment (Grove, Zald, Lebow, Snitz, \& Nelson, 2000; Anderson \& Hanson, 2010). Such findings have facilitated acceptance and a wider implementation of evidencebased tools underpinned by the RNR model. Best practices for these assessment tools include uniform application with standardized measurement, resulting in valid and reliable assessment results used to inform case management. These actuarial assessment tools remove the potential bias, subjectivity, and variability of clinical judgment.

Recent updates to the RNR principles have seen the inclusion of professional override. Professional override was initially defined as, "Having considered risk, need, and responsivity, decisions are made as appropriate under present conditions" (Andrews, Bonta, \& Hoge, 1990, p. 20). Twenty years later, Andrews and Bonta modified this definition to state that "Professional discretion recognizes that professional judgment on rare occasions may override structured decision-making. However, this principle also stresses that the use of professional discretion must be clearly documented" (2010, p. 52). Professional override provides the opportunity for case managers to use discretion and consider information available to them which may not be encompassed in the standardized testing (Andrews \& Bonta, 2010). The intention behind professional override was for scarce application, with user guides stating it should be utilized with caution and justified with documented logic and evidence (Hoge \& Andrews, 2011). Knowledge of how it is used in practice is limited. Research in a youth detention setting found risk assessments were overridden more regularly for offenders of certain demographics (Chappell, Maggard, \& Higgins, 2012). Furthermore, when risk is adjusted, it is most often to increase rather than decrease risk; these studies find that the effect of these overrides reduces predictive validity to the level of chance (Schmidt, Sinclair, \& Thomasdottir, 2016; Wormith, Hogg, \& Guzzo, 2012).

Research has demonstrated that when it comes to noncompliance with risk assessment tools, there are different types of noncompliers. In their study of community corrections 
officers, Miller and Maloney (2013) found that risk assessment tools were usually completed when required to be, but officers sometimes deviated from the results when making their decisions. Approximately half of those who use the tools were called "substantive" compliers, completing the assessments carefully and honestly, tending to use them to inform decisionmaking. The remaining half of the group were named "formal" compliers, as they completed the tools, but regularly ignored the results when making decisions, occasionally even manipulating the information entered into the tool. A study of compliance with risk assessment tools found that some noncompliance occurs by manipulating the tool in order to produce a desired result (Lyle \& Graham, 2000). This finding is replicated in a recent study into self-reported tool compliance in probation and parole officers, where Schaefer and Williamson (2018) found various forms of noncompliance to be commonplace in one community corrections agency. In this study, one-quarter of the sample minimized or exaggerated information entered into the tool in order to secure a preferred outcome. Over half of the sample reported deviation from the risk rating provided by the tool when making their decisions, and one-third of the sample admitted to completing the tool carelessly. These actions occur when the tool is completed at all, with $37 \%$ of the sample reporting that they did not attempt assessment completion in over $30 \%$ of cases. Furthermore, noncompliance with assessment tools was found to be influenced by the supervisory styles favored by individuals. Those staff members who favored surveillance or rehabilitation were less likely to deviate from the tools, while those who preferred opportunity-reduction strategies were more likely to deviate. These discoveries of noncompliance with assessment and case management tools is concerning given the well-documented failings of clinical judgement over standardized, empirically supported, actuarial assessments. 
The importance offender assessment in contemporary community corrections practice cannot be overstated. Instruments that assess offender risks, criminogenic needs, and responsivity factors are widely implemented, informing decisions about case management throughout corrections processes. Yet some research demonstrates that these tools are not always completed or utilized as designed. In tandem, studies show how a variety of staff characteristics can influence the attitudes held by correctional officers regarding the goals of punishment and their job requirements. It is vital to understand how these attitudes inform daily decision-making and the application of assessment tools, given their centrality in contemporary case management practices and their potential pivotal influence on case management outcomes.

\section{Current Study}

Given these available research findings, we hypothesized that probation and parole officers' perceptions of offenders influences (non)compliance with standardized assessment instruments. In view of the enormous influence an individual staff member can have on case management outcomes, empirical investigation into the attitudes of probation and parole staff regarding their supervisees is imperative. This study provides an important contribution toward understanding the attitudes about offenders held by community corrections staff and the effect of those attitudes on professional practices. Our study is guided by the overarching questions: 1) Do the attitudes of probation and parole staff about offenders under community supervision influence their (non)compliance with the data entered for case management tools? If so, in what direction does this relationship operate? 2) Are probation and parole staff members' attitudes about offenders associated with certain role orientations, work strategies, or job stress? 3) Do any of these occupational experiences mediate the relationship between staff attitudes about offenders and their (non)compliance with assessment data entry? 
The current study utilizes data from a survey of probation and parole staff to examine how their attitudes toward offenders influence their use of assessment instruments and case management tools, mediated by several orientation and professional practice scales.

\section{Participants}

All probation and parole staff working in community corrections offices in one large metropolitan region in Australia were invited to participate. Approximately 125 staff were provided with the link for the survey, and 75 surveys were completed (60\%); unfortunately, due to the staffing structure in the agency where the study occurred (most notably floating positions that are shared between regions and shared positions toward a full-time equivalent appointment within regions), it is not possible to give the exact number of staff employed in the region. The calculated response rate of $60 \%$ (based on the number of completed surveys per the number of "seats" in the region) is above average for research that surveys individuals within organizations (Baruch \& Holtom, 2008). The majority of participants are female (86\%). The most frequent position among participants was that of senior case manager (supervising officers who carry a caseload with higher levels of risk, greater criminogenic needs, and more challenging responsivity consdierations; $43.10 \%$ ), followed by case manager (29.40\%), and other roles (such as services officer or program delivery; 27.50\%). The average caseload size was nearly 50 offenders $(M=49.89, S D=28.61)$, and the average length of employment was more than 5 years $(M=66.83$ months, $S D=58.59)$. All participants had a Bachelor's degree as a minimum level of education, with $67 \%$ of the sample having a higher research degree (including Honours, Masters, or Graduate Certificates).

\section{Measures}


Following informed consent procedures, the survey provided questions categorized into six sections: supervision strategies, role orientations, job satisfaction and stress, use of case management tools, attitudes toward offenders, and reporter characteristics. Descriptions of the measures used in this study follow below.

Attitudes toward offenders. A scale measuring probation and parole staff members' attitudes about the offenders they supervise was developed using modified questions from the Attitudes toward Prisoners scale (Melvin, Gramling, \& Gardner, 1985). Three of the questions from the original 36-item scale were not included because they were not relevant to community corrections (e.g., "If a person does well in prison, he should be let out on parole"); the remaining items were adjusted to reflect probation and parole work, such as replacing the word "prisoner" with the word "offender" and substituting "prison" for "probation and parole". Respondents were given a prompt about a summary attitude toward offenders (e.g., "Offenders are different from most people," "Most offenders are victims of circumstance and deserve to be helped," "Probation and parole just make offenders worse"), and were instructed to rate their agreement with the statement $(0=$ strongly disagree through $6=$ strongly agree $)$. Similar to the original survey, here the same questions were reverse-coded to prevent participants from a biased response style of acquiescence or inattention (for a discussion of these methods and their effectiveness, see van Sonderen, Sanderman, \& Coyne, 2013). Comparable to the original scale, the 33 items used here are internally consistent $(\alpha=.797)$, and were combined to form an additive scale $(R=90-173, M=130.68, S D=18.46)$. Higher scores reflect the attitude that offenders are normal people capable of positive change, while lower scores reflect more negative attitudes that offenders are deviants deserving of punishment.

Case management tool data entry scale. To assess the degree to which probation and parole staff are (non)compliant with the data entry processes used with case management tools, the survey included questions drawn from Miller and Maloney (2013). Participants 
were asked to indicate how frequently they engage in particular behaviors while entering data into the instruments used in their work (with responses ranging from $0=$ never through $6=$ always). Instruments used in this agency include a reoffending risk calculator, a baseline assessment used to estimate risk, needs, and responsivity characteristics, and a routine case management tool that is used at every offender contact to gauge change across time. These tools are internal to the agency used in this study, although they share many of the same features as the leading assessment instruments and case management tools used in community corrections around the world. Five survey items were identified as a factor $(\alpha=.752)$, including how often the respondent completes or updates the tool carelessly, makes minimum effort, exaggerates information, minimizes information, or otherwise manipulates information in order to get the desired result. These five items were combined into a mean scale $(R=0$ $2.80, M=.50, S D=.69$ ), with higher scores reflecting more incidences of manipulating risk and needs assessments and case management tools.

Role and strategy orientations. A set of questions reflecting the professional orientations of staff was utilized, replicating the measures used by Fulton, Stichman, Travis, and Latessa (1997). The questions rely on ten-point semantic differentials which measure participants' reactions to pairs of words or concepts that are opposite in meaning (Heise, 1971; Mueller, 1986). For example, survey respondents were given the prompt, "As a case manager, your primary obligation is to:"; they were then given two anchors, "rehabilitate the offender" (on one end of the scale), and "enforce conditions of supervision" (on the other end of the scale), requiring the participant to select a number on the scale (from 1-10) that places their orientation somewhere on that spectrum. A total of nine semantic differentials were used to reflect two underlying scales. Questions were presented in mixed order with periodic reverse-coding. First, the subjective role scale is comprised of five items, measuring what probation and parole officers do. The items loaded on one factor $(\alpha=.773)$ with loadings of greater than .71 , and were therefore combined into a summative scale $(R=11-45, M=25.03$, 
$S D=7.41$ ). Lower scores reflect more liberal role orientations, while higher scores are indicative of more conservative orientations to offender supervision; scores that approximate the true mean for the scale $(M=25)$ reflect a balanced role orientation between these two anchors. Second, the strategy scale includes four items, measuring how probation and parole perform the functions of their job. These four items loaded on one factor $(\alpha=.695)$ with loadings of greater than .70 , and were likewise combined into a summative scale $(R=7-24, M$ $=16.83, S D=4.29)$. Lower scores reflect rehabilitative strategies while higher scores reflect strategies that emphasize control or punishment; scores that approximate the true mean for the scale $(M=20)$ reflect a balanced use of these strategies.

Job burnout and stress. The Maslach Burnout Inventory (Maslach \& Jackson, 1981) was used to measure job burnout and stress among probation and parole staff. The inventory includes 22 items prompting participants to indicate how frequently they experience certain feelings as the result of their job $(0=$ never, $1=$ a few times a year, $2=$ once a month or less, $3=$ a few times a month, $4=$ once a week, 5 = a few times a week, $6=$ everyday). The statements are configured around three separate dimensions, aggregated into mean scales. Personal accomplishment is comprised of eight items $(\alpha=.738, R=2.25-5.75, M=4.33, S D$ $=.86)$ such as "I have accomplished many worthwhile things in this job." Depersonalization includes five items $(\alpha=.705, R=0-3.60, M=1.20, S D=.87)$ such as "I feel I treat some offenders as if they were impersonal objects." Emotional exhaustion is composed of nine items $(\alpha=.881, R=.11-5.00, M=2.01, S D=1.06)$ such as "Working with offenders all day is a real strain for me." Higher scores on the personal accomplishment scale reflect less burnout and stress, while higher scores on the depersonalization and emotional exhaustion scales are indicative of greater levels of job burnout and stress.

\section{Procedures}


An email invitation to participate in the survey was sent to the regional manager of all probation and parole offices in a large metropolitan area in Australia. The regional manager then forwarded the email to all operational staff in the region. The email provided informed consent information, advising that participation was voluntary and anonymous. Also included were instructions on how to access and complete the survey, including a link to the instrument, hosted online. In order to access the survey items, respondents first had to provide anonymous informed consent. On average, participants took 18 minutes to complete the survey ( $S D=6$ minutes), as reported by the online data collector. Staff were not provided any compensation to participate in the survey and were advised that they would not be (dis)benefited by their decision to complete the survey or abstain.

Of the 75 completed surveys, approximately 30 had no missing data at all; the remaining surveys had at least one missing response, with some surveys missing entire sections of entered data. Although every effort was made to guarantee the anonymity of the survey respondents, some participants may have worried that the researcher would be able to link individual responses to employees, or that the manager or employer would learn the participant's responses. The invitation to complete the survey was issued via work email, and staff are unable to access their work email outside of the office (and are further prohibited from forwarding work emails to personal addresses). The result of these policies means that study participants were only able to complete the survey while at work and at their desk. The probation and parole offices in the agency use open floor plans with computers arranged in pods, and thereby anyone walking by is able to view what is on the computer. It is possible that some staff may have felt uncomfortable answering each question knowing that their responses could be observed by colleagues. Some of the missing data in the current study may be a consequence of these factors. 
Following from these matters, the sample size for some of the analyses was smaller than 75. For the variables used in this study, where data were missing, the percentage ranged from just $2 \%$ to $16 \%$. Missing values analyses demonstrate that these data are missing at random, which were replaced using multiple imputation (Zhang, Wang, \& Tong, 2015). The proportion of missing data slowly climbed as the survey progressed, perhaps representing the pressure individuals felt to complete the survey quickly. Given these considerations and the theoretical model we have proposed here, this project relies on mediation analysis with bootstrapping as the analytic approach, drawing on the methodology outlined by Hayes (2013). Mediation analyses examine the effects of mediators $M_{\mathrm{i}}$ on the relationship between how some independent variable $X$ exerts influence on some outcome variable $Y$. That is, how variation in $X$ causes variation in $M$, which then in turn causes variation in $Y$. When the $a$ path (the relationship between $X$ and $M$ ) and $b$-path (the relationship between $M$ and $Y$ ) are both significant, mediation analysis tests the strength and significance of the direct and indirect effects of $X$ on $Y$. Bootstrapping is used to resample with replacement to produce bias-corrected confidence interval estimates, ${ }_{\mathrm{T}} a_{\mathrm{T}} b$ (MacKinnon, Lockwood, \& Williams, 2004; Preacher \& Hayes, 2004), using a 95\% confidence interval around the indirect effect using 5,000 bootstrap resamples (Preacher \& Hayes, 2008). Here we model and test a parallel multiple mediator model (Hayes, 2013) in which several mediators are thought to influence the relationship between the independent and dependent variables without the mediators themselves being causally associated. These pathways are estimated through a series of ordinary least squares regression equations.

The analyses conducted here were completed in four phases. First, the data were prepared for model estimations, including scale creation and the management of missing data through multiple imputation and bootstrap (Zhang, Wang, \& Tong, 2015). Second, the direct effect between probation and parole staff members' attitudes toward offenders and (non)compliance with case management tools was examined. Third, the indirect effects of 
these attitudes on (non)compliance with instrument data entry were explored, utilizing five scales as mediating variables: subjective role orientation, strategy orientation, personal accomplishment, depersonalization, and emotional exhaustion. Fourth, the significant indirect relationships were examined in a separate final model. The values included along the paths between two variables represent the regression coefficients, having controlled for other paths in the model.

\section{Results}

\section{Direct effects}

In examining the relationship between the attitudes of probation and parole staff toward offenders and their influence on the (non)compliance with the data entry processes for case management tools, there is a moderate, positive, and significant direct effect $(\beta=.0125$, $p<.05)$. Statistically, this indicates that for each one-unit increase in the attitudes toward offenders scale, there is a corresponding increase in the case management tool scale of .0125 $(R=0-2.80)$. Practically, this specifies that more optimistic attitudes about offenders (i.e., that probationers and parolees are normal individuals that can achieve positive behavioral and lifestyle change) leads to increased frequencies of noncompliant data entry processes used with risk and needs assessment and case management tools. Contrarily, more pessimistic attitudes are associated with greater compliance with the data entry requirements of these tools.

We acknowledge that the motivation that undergirds each of the actions included in the overall scale differ; being careless with data entry is substantively different than intentionally exaggerating the data that is entered, for example. Thus, in order to determine whether these items operate in different ways or if there were some items that are driving the overall relationship, we compared the attitude toward offenders scale for groups of staff that reported occasional noncompliance with data entry in risk and needs assessments versus those 
who did not. Probation and parole staff who reported that they sometimes complete the tool carelessly (49\%) had more optimistic attitudes about the offenders they supervise $(t=-2.239$, $p<.05)$. This relationship was consistent across the other items from the case management tool scale, with noncompliance being associated with higher scores on the attitudes toward offenders scale. These more positive attitudes, reflecting notions that probationers and parolees are like non-offenders and they are capable of change, were seen among staff who reported occasionally making minimum effort in completing risk and needs assessment tools $(37 \%, t=-4.295, p<.001)$, exaggerating the information they enter into the tool $(22 \%, t=-$ $1.982, p=.051)$, minimizing the information entered $(26 \%, t=-2.359, p<.05)$, or otherwise manipulating the information entered $(22 \%, t=-2.589, p<.05)$. Summarily then, across all items on the overall scale, more pessimistic attitudes about offenders are associated with greater compliance with data entry processes used in the completion of risk and needs assessments.

\section{Indirect effects}

This is somewhat of a peculiar finding, as we had initially speculated that a greater belief in offenders' capacity for rehabilitation and desistance would be associated with greater trust in organizational goals and an increased belief in the validity of the prescribed case management tools, which would then lead to staff completing these assessments as instructed. As a result of this relationship, we then hypothesized that this association may be the consequence of several mediating variables. In particular, we estimated that if probation and parole staff members' attitudes toward offenders influenced 1) the way they approach their job, 2) the strategies they use in their job, or 3) the levels of burnout and stress that they experience, that this could in turn impact the frequency with which they adhere to or manipulate the information reported in case management tools. To explore these relationships, we constructed a parallel multiple mediator model. 
As seen in Figure 1, the staff member's attitudes toward offenders are significantly associated with all five mediator variables. First, the attitudes scale is negatively associated with the role orientation scale $(\beta=-.1519, p<.05)$, demonstrating that more hopeful attitudes about supervisees leads to more liberal role orientations. Next, there is a negative relationship between the case manager's attitudes toward probationers and parolees and the strategies that they utilize in the course of their work $(\beta=-.0827, p<.05)$, whereby more positive attitudes are associated with more rehabilitative strategies and more negative attitudes lead to the use of more punitive approaches to case management. Third, the staff member's attitudes toward offenders is positively associated with reported levels of personal accomplishment $(\beta=.0158$, $p<.05$ ), such that more optimistic attitudes about supervisees leads to a greater sense of achievement in the completion of probation and parole work. Fourth, there is a negative association between the attitudes scale and the respondent's sense of depersonalization $(\beta=$ $.0801, p<.05)$, indicating that more hopeful attitudes about offenders' capacity for change is related to diminished experiences of depersonalizing the offenders on their caseload. Finally, the attitudes scale is negatively associated with participants' reported levels of emotional exhaustion $(\beta=-.0607, p<.05)$, whereby the emotional drain experienced in case management work is lowered by more optimistic attitudes about offenders.

Each of these relationships operate in the expected direction of effect. However, in the full mediation model, examining how the attitudes of the staff member toward offenders impacts their (non)compliance with the data entry processes of these case management tools through each of these five mediators, only one indirect effect is significant. Specifically, the relationship between personal accomplishment and (non)compliance is moderate and positive $(\beta=.3146, p<.05)$. Directly, this indicates that a greater sense of achievement from the case manager is associated with increased frequencies with which he or she is noncompliant with assessment instruction for how to enter data into those instruments; that is, that probation and parole staff who indicate that they feel accomplished, effective, or successful in their work 
with offenders are more likely to indicate that they are noncompliant with the requirements of data entry for the tools they use as part of that job. Although all of the mediator variables were significantly related to the independent variable, the other four mediators were not significant in their indirect effects of the relationship between the attitudes scale and the tool scale; role orientation, strategy orientation, depersonalization, and emotional exhaustion did not significantly mediate the positive association between the attitudes of staff about offenders and their reported (non)compliance with case management tools.

\section{Partial effects}

As seen in Figure 2, we next isolated the significant pathways, estimating the direct and indirect effects separate from the nonsignificant mediating pathways in Figure 1. The indirect effect was significant, whereby the staff member's attitudes toward offenders positively influenced their sense of personal accomplishment $(\beta=.0189, p<.05)$, and the sense of personal accomplishment was positively associated with noncompliance with the completion of case management tools $(\beta=.2958, p<.05)$. The direct effect between the attitudes scale and the case management tool scale reduced in magnitude but remained significant $(\beta=.3146, p<.05)$, indicating that the personal accomplishment scale partly mediated the relationship between the independent and dependent variables. The model exhibits a small but significant fit $(F=4.3201, p<.05)$ and proportion of variance explained $\left(R^{2}=.2233\right)$. Overall, these relationships demonstrate that while more optimistic attitudes about probationers and parolees leads to increased frequencies of tool noncompliance, this relationship can be accounted for, in part, by the sense of personal accomplishment achieved through community corrections work. Practically, this indicates that having more positive perceptions regarding offenders' capacity for change leads to a greater sense of satisfaction on the job, which in turn leads to greater levels of noncompliance with data entry processes required for the use of assessment and case management tools. 
The direction of effect between the attitudes scale and job satisfaction seems reasonable, although the direction of influence between personal accomplishment in work and noncompliance with case management tools' data entry was unexpected. In speculating about this relationship, we hypothesized that perhaps a greater sense of personal accomplishment in performing probation and parole work would be associated with a heightened sense of confidence; this confidence then, may be associated with a heightened belief that clinical judgment is superior to empirically validated actuarial tools, hence leading to greater manipulation of the data entry process used with these instruments. One of the items from the survey that asked about job satisfaction prompted participants with the statement, "I feel confident in my abilities as a case manager," asking them to indicate how frequently they experience this sentiment (from $0=$ never to $6=$ everyday). The association between confidence in case management abilities and noncompliance with data entry processes within case management tools is strongly and significantly negative (Spearman's $\rho=-.616, p<$ .001 ), opposite to the effect of personal accomplishment as a total scale on tool noncompliance. Interestingly, an individual's sense of personal accomplishment and their confidence in their professional abilities in probation and parole work are moderately and significantly positively associated (Spearman's $\rho=.373, p<.01$ ), despite having different directions of effect on noncompliance with case management tool use. The staff member's attitudes toward offenders are not related to reported confidence in case management abilities (Spearman's $\rho=.014, p=.925$ ). Likewise, attitudes toward offenders, personal accomplishment, and confidence were not significantly associated with the individual's perceived validity of the case management tools (we used the same scale employed by Miller \& Maloney, 2013), although the staff member's perception of the validity of those tools was negatively associated with noncompliance with data entry (Spearman's $\rho=-.295, p<.05$ ). Thus, although ideas about professional judgment versus actuarial assessment seem relevant here (with heightened beliefs about the case management tools being valid assessments 
leading to more noncompliance in the use of those tools), the perceived validity of the tools is unrelated to confidence or accomplishment as a case manager.

\section{Discussion}

Following from the principles of effective correctional intervention, actuarial risk and needs assessments are at the center of contemporary community corrections practices. These case management tools are used to guide staff decision-making about the services and surveillance each offender will receive and are therefore critical to probation and parole outcomes. Yet some research has demonstrated that corrections staff do not always adhere to these tools as designed, failing to comply with data entry processes or sidestepping the recommendations of these instruments (Bonta et al., 2008; Miller \& Maloney, 2013). While some degree of "professional override" is expected, studies have shown that corrections practitioners may be intentionally manipulating the information used in case management tools in order to achieve a desired outcome or are being careless in how these tools are completed (Lyle \& Graham, 2000; Schaefer \& Williamson, 2018). Thus, while further research is needed about how probation and parole staff use these assessments (Harris, 2006), scholars must also begin to investigate the factors that influence (non)compliance with case management tools. Accordingly, this study utilized data from a survey of probation and parole staff to explore how their attitudes about offenders impact their (mis)use of these instruments, mediated through several professional orientations.

Principally, the results demonstrated that the attitudes held by probation and parole staff about offenders were significantly associated with noncompliance with case management tools, whereby more pessimistic attitudes were associated with greater compliance with data entry, and more optimistic attitudes with increased occurrences of noncompliance. This is an important finding, demonstrating that corrections practitioners do not approach case management tools open-mindedly, but like many other aspects of their 
work, they may be influenced in their performance of the job based on their preconceived ideas about offenders (which are the product of experience, at least in part). Research is fairly consistent in demonstrating that an officer's orientation to his or her work impacts actual supervision practices (Ricks \& Eno Louden, 2015), so it is important to investigate the factors that influence these orientations. This study has highlighted the significance of offender supervisors' attitudes about their supervisees in impacting such practices.

With this finding in mind, and combined with the results from relevant studies, we further wondered whether the relationship between these attitudes about offenders and noncompliance with the data entry processes of case management tools was mediated by professional orientations. Indeed, more optimistic attitudes about probationers and parolees is associated with more liberal role orientations, greater use of rehabilitative strategies, a greater sense of personal achievement, less depersonalization of offenders, and less emotional exhaustion. These results again showcase the influential role of how the attitudes of correctional staff impact their work. Yet interestingly, only one of these relationships was significant in its subsequent impact on tool noncompliance, whereby more positive attitudes about offenders led to a greater sense of personal accomplishment, which in turn lead to increased noncompliance with the data entry process of risk and needs assessments.

Perhaps the most important finding from this study is that, while probation and parole staff members' attitudes toward offenders impact their noncompliance with case management tools (such that more optimistic attitudes leads to greater noncompliance with the data entry processes required by these instruments), this relationship is mediated by the individual's sense of personal accomplishment in their job. As shown in the mediation analysis in Figure 2, more positive attitudes about offenders leads to a heightened sense of professional accomplishment, although this subsequently leads to greater noncompliance with the information entered into case management tools. Contrary to our best guess, this result does not appear to be the consequence of increased staff confidence, which was negatively 
associated with risk and needs assessment noncompliance. One possible explanation for this may be the nuanced but critical distinction between self-confidence and self-efficacy (Bandura, 1997), which could reasonably exert different effects on the (non)compliance with case management tools. Confidence refers to a general belief about one's worth and ability to succeed, while self-efficacy is often task-specific. Indeed, those who are highly selfefficacious can create optimal environments that promote success and avoid failure. Seen in this way, it is possible that confidence in one's ability as a probation or parole practitioner leads to greater compliance with case management tools due to a prevailing belief in the ability to effectively supervise offenders irrespective of the recommendations of case management tools. Contrarily, a sense of personal accomplishment in the job may enhance the individual's perceived efficacy toward case management in such a way as to influence the one specific task of professional override with case management tools. If an individual officer has optimistic attitudes about the offenders that he or she supervises, this may lead to tool noncompliance through an enhanced sense of accomplishment following from previous experiences of successful outcomes stemming from such sidesteps. This finding provides an interesting insight into the context in which these assessments are (mis)used, demonstrating some of the difficulties in translating evidence-based best practices into widespread operational routines for front-line staff.

One critical consideration of these findings is the motivation for tool noncompliance; probation and parole staff may be failing to adhere to the data entry instructions of these assessments due to apathy, fraudulence, or beneficence, and each may seem justifiable in the operational context where staff perform their work. In this study, approximately half of the staff surveyed indicated they sometimes complete case management tools carelessly, and more than one-third reported that they at least periodically make minimum effort in completing these instruments. Practically, this does not have to infer a lack of concern for the job; rather, this may represent a sentiment among staff that the results of the tool do not 
matter, therefore the information entered is inconsequential. Contrarily, approximately onequarter of the sample indicated that they minimize information entered into the tool and onefifth reported exaggerating information. This reality may be less about conflict between organizational values and an individual's occupational identity (Mawby \& Worrall, 2013) and more about the implications of these tool outcomes. Resource constraints, for example, may make certain recommendations unfeasible, so staff may be "manipulating" the data entered into the instrument to avoid receiving a result that cannot practically be addressed (Gebo et al., 2006; Schaefer \& Williamson, 2018; Shook \& Sarri, 2007). Using this latter justification as a theoretical mechanism, the current study's finding that links more optimistic attitudes with greater noncompliance may be due to probation and parole staff aiming to obtain assessment results that allow their clients to achieve the change they are believed to be capable of. While research has begun to unpack the extent to which corrections staff are noncompliant with risk and needs assessments, further empirical investigation is required to discover why staff misrepresent the data entered into these tools.

\section{Limitations}

The contributions of this current project aside, the current study is not without limitations. First, the sample size was not large enough to permit more sophisticated analytic modeling and may hamper the generalization of the findings. Some of this was surmounted using bootstrapping, and as an exploratory study, the results provide a promising direction for subsequent research. Second, there were some problems with missing data, perhaps due to participants' worries of having their identity linked to their responses or being observed in the completion of the study. The link for the survey was sent to employees' work email and could only be accessed from a work computer; thus, despite our best efforts to promise anonymity, these concerns may have impacted staff members' completion of the survey. Third, staff were asked to self-report their own behavior, which comes with challenges. The 
survey participants may be biased in the way they reflect on their own attitudes and work performance, or biased in the way that they represent themselves in their survey responses. Fourth, although the parallel multiple mediator model provides important insights into the direction of effects, it is not possible to test for reciprocating effects here. It is possible that some of the mediating variables actually influence the staff member's attitudes about offenders, creating a perpetual feedback loop. While supplementary analyses not fully reported here show that the relationships are maintained when $\mathrm{X}$ and $\mathrm{Y}$ are exchanged $\left(\beta \_X_{\text {noncompliance }}=.327 \rightarrow \beta \_M_{\text {accomplishment }}=.483 \rightarrow \mathrm{Y}_{\text {attitudes }}\right)$, better data is required to fully unpack directionality and reciprocation. Further studies are needed to examine some of these more complex non-recursive models, unpacking how the attitudes of corrections staff about the offenders they work with affect professional practices, which then go on to reinforce or challenge attitudes.

\section{Conclusions}

In spite of these limitations, the current study offers a number of important implications for corrections research and practice. Correctional scholarship should further investigate the role of staff members' attitudes toward correctional clients on their professional practices. Moreover, further information is needed about the ways in which case management tools are approached and utilized by the staff that routinely use them. While the research evidence-base has conclusively demonstrated the predictive validity of actuarial offender risk assessments, the utility of risk and needs assessments in probation and parole practice may be overestimated if the users of these instruments are applying their discretion in ways that invalidate them. Importantly, however, as uncovered in this study, the (mis)use of these tools is impacted by practitioners' attitudes about their supervisees and subsequent orientations to their work; the finding that more optimistic attitudes about offenders was associated with noncompliance with assessment data entry processes suggests that staff may 
be sidestepping the requirements of case management tools for altruistic purposes, prompting the need for further research that examines this symbiotic relationship. 


\section{References}

Anderson, D., \& Hanson, R.K. (2010). Static-99 an actuarial tool to assess risk of sexual and violent recidivism among sexual offenders. In R.K. Otto \& K.S. Douglas (Eds.), Handbook of violence risk assessment (pp. 251-268). New York, NY: Routledge.

Andrews, D. A., \& Bonta, J. (2010). The psychology of criminal conduct $\left(5^{\text {th }}\right.$ ed.). New Providence, NJ: LexisNexis.

Andrews, D. A., Bonta, J., \& Hoge, R. D. (1990). Classification for effective rehabilitation: Rediscovering psychology. Criminal Justice and Behavior, 17, 19-52.

Andrews, D.A., Bonta, J., \& Wormith, S.J. (2006). The recent past and near future of risk and/or need assessment. Crime \& Deliquency, 52(1), 7-27.

Bandura, A. (1997). Self-efficacy: The exercise of control. New York: Freeman.

Baruch, Y., \& Holtom, B. C. (2008). Survey response rate levels and trends in organizational research. Human Relations, 61(8), 1139-1160.

Beijersbergen, K. A., Dirkzwager, A. J. E., Molleman, T., van der Laan, P. H., \& Nieuwbeerta, P. (2015). Procedural justice in prison: The importance of staff characteristics. International Journal of Offender Therapy and Comparative Criminology, 59(4), 337-358.

Bonta, J., Rugge, T., Scott, T., Bourgon, G., \& Yessine, A. (2008). Exploring the black box of community supervision. Journal of Offender Rehabilitation, 47(3), 248-270.

Chappell, A.T., Maggard, S.R., \& Higgins, J.L. (2012). Exceptions to the rule? Exploring the use of overrides in detention risk assessment. Youth Violence and Juvenile Justice, $11(4), 332-348$.

Conley, T., Hill, K., Church, W. T., Stoeckel, E., \& Allen, H. (2011). Assessing probation and community corrections workers' attitudes toward sex offenders using the Community Attitudes Toward Sex Offenders (CATSO) scale in a rural state. Sexual Addiction \& Compulsivity, 18(2), 75-85. 
Craig, L. A. (2005). The impact of training on attitudes towards sex offenders. Journal of Sexual Aggression, 11(2), 197-207.

Farkas, M.A. (1999). Correctional officer attitudes toward inmates and working with inmates in a "get tough" ear. Journal of Criminal Justice, 27(6), 495-506.

Fulton, B., Stichman, A., Travis, L., \& Latessa, E. (1997). Moderating probation and parole officer attitudes to achieve desired outcomes. The Prison Journal, 77, 295-312.

Gebo, E., Stracuzzi, N. F., \& Hurst, V. (2006). Juvenile justice reform and the courtroom workgroup: Issues of perception and workload. Journal of Criminal Justice, 34, 425433.Grove, W.M., Zald, D.H., Lebow, B.S., Snitz, B.E., \& Nelson, C. (2000). Clinical versus mechanical prediction: A meta-analysis. Psychological Assessment, 12(1), 19-30.

Harris, P. M. (2006). What community supervision officers need to know about actuarial risk assessment and clinical judgment. Federal Probation, 70(2), 8-14.

Hayes, A. F. (2013). Introduction to mediation, moderation, and conditional process analysis: A regression-based approach. New York: Guilford.

Heise, D. J. (1971). The semantic differential and attitude research. In C. E. Osgood, G. J. Suci, \& P. H. Tannenbaum (Eds.), The measurement of meaning (pp. 235-253). Urbana: University of Illinois Press.

Hemmens, C., \& Stohr, M.K. (2000). The two faces of the correctional role: An exploration of the value of the correctional role instrument. International Journal of Offender Therapy and Comparative Criminology, 44(3), 326-349.

Hoge, R.D., \& Andrews, D.A. (2011). Youth Level of Service/Case Management Inventory 2.0 (YLS/CMI) user's manual. Toronto, Canada: Multi-Health Systems.

Maahs, J., \& Pratt, T. (2001). Uncovering the predictors of correctional officers' attitudes and behaviors: A meta-analysis. Corrections Management Quarterly, 5(2), 13-19. 
MacKinnon, D. P., Lockwood, C. M., \& Williams, J. (2004). Confidence limits for the indirect effect: Distribution of the product and resampling methods. Multivariate Behavioral Research, 39, 99-128.

Maslach, C., \& Jackson, S. (1981). The measurement of experienced burnout. Journal of Occupational Behavior, 2, 99-113.

Melvin, K. B., Gramling, L. K., \& Gardner, W. M. (1985). A scale to measure attitudes toward prisoners. Criminal Justice and Behavior, 12, 241-253.

Miller, J., \& Maloney, C. (2013). Practitioner compliance with risk-needs assessment tools: A theoretical and empirical assessment. Criminal Justice and Behavior, 40, 716-736.

Mueller, D. J. (1986). Measuring social attitudes: A handbook for researchers and practitioners. New York: Teachers College Press.

Nelson, M., Herlihy, B., \& Oescher, J. (2002). A survey of counselor attitudes towards sex offenders. Journal of Mental Health Counseling, 24(1), 51-67.

Preacher, K. J., \& Hayes, A. F. (2004). SPSS and SAS procedures for estimating indirect effects in simple mediation models. Behavior Research Methods, Instruments, and Computers, 36, 717-731.

Preacher, K. J., \& Hayes, A. F. (2008). Asymptotic and resampling strategies for assessing and comparing indirect effects in multiple mediator models. Behavior Research Methods, 40, 879-891.

Rade, C.B., Desmarais, S.L., \& Mitchell, R.E. (2016). A meta-analysis of public attitudes toward ex-offenders. Crime Justice and Behavior, 43(9), 1260-1280.

Ricks, E. P., \& Eno Louden, J. (2015). The relationship between officer orientation and supervision strategies in community corrections. Law and Human Behavior, 39(2), 130141.

Roberts, J. (2018). Public opinion, crime, and criminal justice. Routledge: New York. 
Schaefer, L., \& Williamson, H. (2018). Probation and parole officers' compliance with case management tools: Professional discretion and override. International Journal of Offender Therapy and Comparative Criminology, 62(14), 4565-4584.

Schmidt, F., Sinclair, S.M., \& Thomasdottir, S. (2016). Predictive validity of the youth level of service/case management inventory with youth who have committed sexual and nonsexual offenses. Criminal Justice and Behavior, 43(3), 413-430.

Schwalbe, C. S., \& Maschi, T. (2009). Investigating probation strategies with juvenile offenders: The influence of officers' attitudes and youth characteristics. Law and Human Behavior, 33(5), 357-367.

Shook, J. J., \& Sarri, R. C. (2007). Structured decision making in juvenile justice: Judges' and probation officers' perceptions and use. Children and Youth Services Review, 29, 13351351. Spiranovic, C.A., Roberts, L.D., \& Indermaur, D. (2012). What predicts punitiveness? An examination of predictors of punitive attitudes towards offenders in Australia. Psychiatry, Psychology and Law, 19(2), 249-261.

van Sonderen, E., Sanderman, R., \& Coyne, J. C. (2013). Ineffectiveness of reverse wording of questionnaire items. PLoS One, 8(7), e68967.

Whetzel, J., Paparozzi, M., Alexander, M., \& Lowenkamp, C. T. (2011). Goodbye to a wornout dichotomy: Law enforcement, social work, and a balanced approach. Federal Probation, 75(2), 7-12.

Wormith, S.J., Hogg, S., \& Guzzo, L. (2012). The predictive validity of a general risk/needs assessment inventory on sexual offender recidivism and an exploration of the professional override. Criminal Justice Behavior, 39(12), 1511-1538.

Zhang, Z., Wang, L., \& Tong, W. (2015). Mediation analysis with missing data through multiple imputation and bootstrap. Quantitative Psychology Research, 140, 341-355. 
Figure 1: Parallel Multiple Mediator Model of Attitudes toward Offenders on Case Management Tool Manipulation 


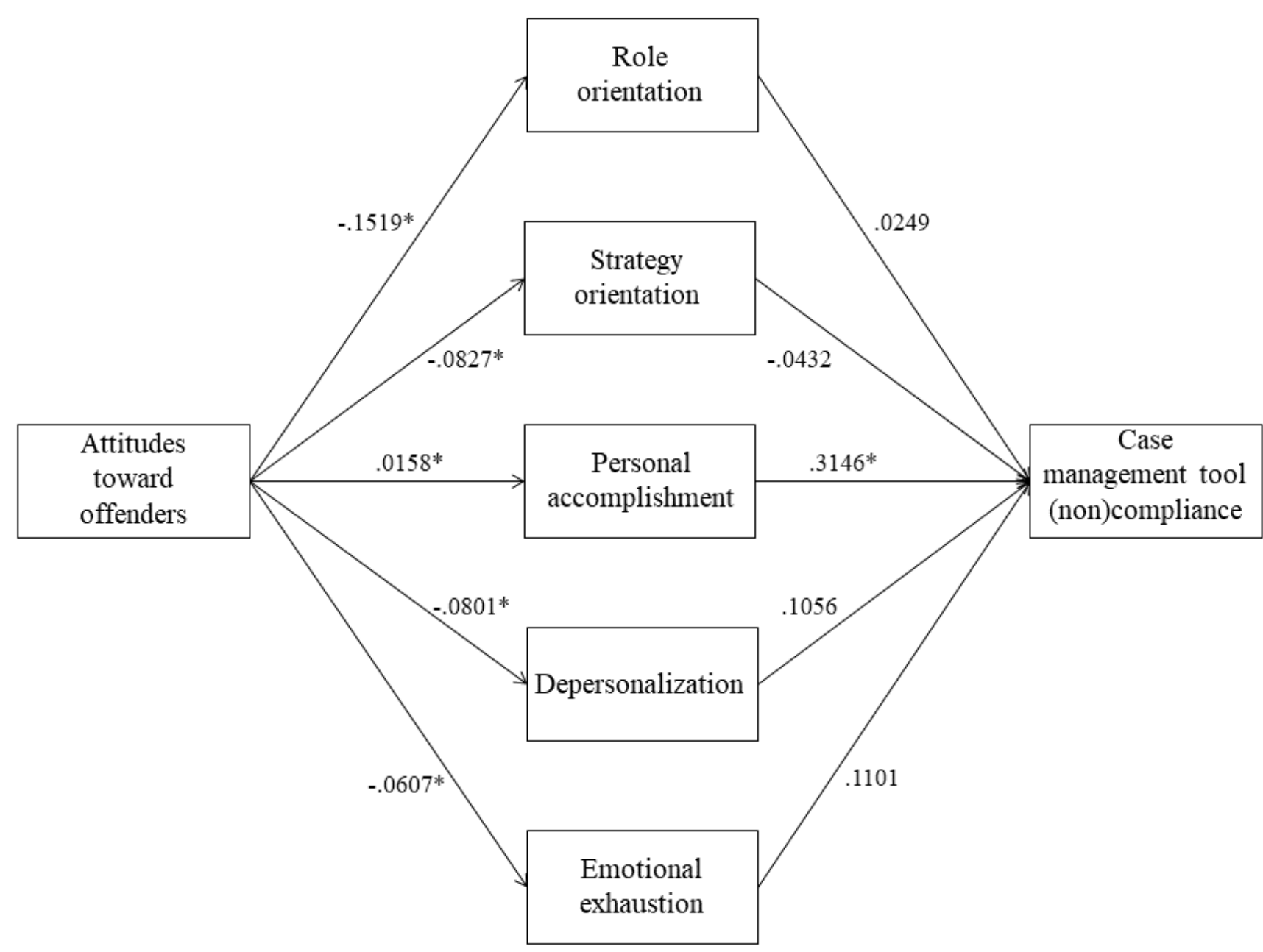

Model summary statistics: $F=10.419, p<.05 ; R^{2}=.195 ;$ MSE $=33.891$ 
Figure 2: Mediation Analysis of Attitudes toward Offenders on

Case Management Tool Manipulation through Personal Accomplishment 


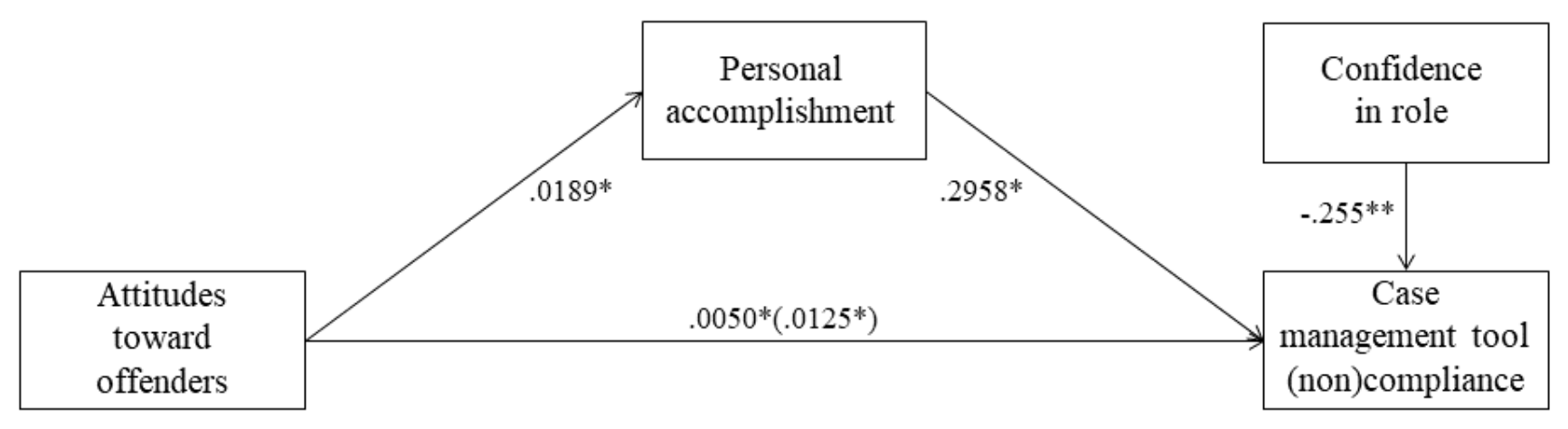

Model summary statistics: $F=4.320, p<.05 ; R^{2}=.161 ; M S E=.383$ 